\title{
Pratiques
}

Linguistique, littérature, didactique

183-184| 2019

oralité, littératie

\section{Ong, Walter J.}

Jean-Marie Privat

\section{(2) OpenEdition}

Journals

Édition électronique

URL : https://journals.openedition.org/pratiques/6767

DOI : $10.4000 /$ pratiques. 6767

ISSN : 2425-2042

\section{Éditeur}

Centre de recherche sur les médiations (CREM)

Référence électronique

Jean-Marie Privat, « Ong, Walter J. », Pratiques [En ligne], 183-184 | 2019, mis en ligne le 30 décembre 2019, consulté le 28 juin 2022. URL : http://journals.openedition.org/pratiques/6767 ; DOI : https:// doi.org/10.4000/pratiques.6767

Ce document a été généré automatiquement le 9 octobre 2020.

(c) Tous droits réservés 


\title{
Ong, Walter J.
}

\author{
Jean-Marie Privat
}

1 W. J. Ong (1912-2003), jésuite de formation, a soutenu une thèse en 1955 à l'université d'Harvard, sous la direction de M. McLuhan (1977 [1962]), le fameux auteur de La Galaxie Gutenberg. La genèse de l'homme typographique. W. Ong a enseigné et conduit l'essentiel de ses recherches à l'Université de Saint-Louis (USA) ${ }^{1}$. On prendra une première mesure de son œuvre riche, diverse, importante et stimulante en anthropologie historique, culturelle et linguistique, en feuilletant An Ong Reader. Challenges for Further Inquiry (Ong, 2002).

2 Les travaux de Ong ont fait véritablement irruption dans l'univers académique francophone avec la traduction - tardive - de son livre Oralité et écriture ${ }^{2}$. Les démonstrations linguistiques et les interrogations anthropologiques de W. Ong sur les dynamiques de l'oralité et sur les logiques de la communication écrite (parole religieuse, acte philosophique, genre littéraire, relation pédagogique) croisent évidemment les recherches décisives d'un J. Goody (1978 [1977]) sur la raison graphique ou, par exemple, celles très importantes et pionnières de l'historienne américaine E. L. Eisenstein sur La Révolution de l'imprimé: à l'aube de l'Europe moderne (Goody, 1991 [1983]).

3 Le point nodal d'Oralité et écriture est toutefois l'émergence de la question des oralités dans les pratiques savantes ou ordinaires et chez les théoriciens (Ong fut un très grand spécialiste des théoriciens renaissants de l'écriture et de la conquête scripturale du monde) et plus encore les négociations plus ou moins conflictuelles et inventives entre culture orale multiforme et univers des écrits ${ }^{3}$. Ong s'est particulièrement intéressé à l'écologie des médias, à la technologie de la parole, au rôle de l'auditoire et il a donné de nombreuses conférences (Lincoln Lecture) sur les façons de raconter et sur la phénoménologie de la lecture (la mémoire, l'intériorité, l'oralité du langage, etc.). C'est la découverte de cette production matérielle et contrastive de la pensée du monde et de la conscience au monde qui a suscité chez le philosophe P. Macherey un passionnant compte rendu d'Oralité et écriture.

4 Nous suggérons à nos lectrices et lecteurs qui découvriraient à leur tour ce continent conceptuel - le nôtre aujourd'hui à chacune et à chacun à vrai dire - de suivre 
P. Macherey dans sa découverte empathique et critique d'un ouvrage qui synthétise les points saillants d'une pensée originale, curieuse et inquiète, une pensée situationniste pourrait-on dire des praxis langagières : https://philolarge.hypotheses.org/1492.

\section{BIBLIOGRAPHIE}

EISENSTEIN, E. L. (1991) [1983]. La Révolution de l'imprimé : à l'aube de l'Europe moderne. Trad. de l'anglais par M. Sissung \& M. Duchamp. Paris : La Découverte.

GoODY, J. (1978) [1977]. La raison graphique : la domestication de la pensée sauvage. Trad. de l'anglais par J. Bazin \& A. Bensa. Paris : Éditions de Minuit.

OLSON, D. R. (1998) [1994]. L'univers de l'écrit. Comment la culture écrite donne forme à la pensée. Trad de l'anglais par Y. Bonin. Paris : Retz.

ORLSON, D. R. (2006). « Littératie, scolarisation et cognition. Quelques implications de l'anthropologie de Jack Goody ». Pratiques 131-132, p. 83-94. En ligne : https://www.persee.fr/ doc/prati_0338-2389_2006_num_131_1_2119.

MCLUHAN, M. (1977) [1962]. La Galaxie Gutenberg. La genèse de l'homme typographique. Trad. de l'anglais par J. Paré. Paris : Gallimard.

ONG, W. J. (2002). An Ong Reader: Challenges for Further Inquiry. Cresskill : Hampton Press. ONG, W. J. (2014) [1982]. Oralité et écriture. La technologie de la parole. Trad. de l'anglais par H. Hiessler. Paris : Les Belles Lettres.

\section{NOTES}

1. The Ong Center at Saint Louis University a été créé en sa mémoire (https:// www.slu.edu/arts-and-sciences/ong-center/walter-ong.php). On pourra consulter de nombreuses transcriptions de contributions orales - y compris en français - à la rubrique Walter J. Ong Manuscript Collection - Archives du site http://cdm.slu.edu/cdm/ landingpage/collection/ong/

\section{J. Ong (2014 [1982]).}

3. À titre de premier contact, on pourra écouter sur YouTube Walter Ong - Oral Cultures and Early Writing. Ong a inspiré de nombreux chercheurs, en particulier David R. Olson (1998 [1994] ; 2006). 


\section{AUTEUR}

JEAN-MARIE PRIVAT

Université de Lorraine, Crem, F-57000 Metz, France 